Original Research Article

\title{
Patterns of acne prescriptions: a study in a tertiary care unit
}

\author{
Donepudi Pavan Kumar*
}

Department of Pharmacology, NRI Medical College, Guntur, Andhra Pradesh, India

Received: 27 April 2019

Accepted: 02 May 2019

\section{*Correspondence to:}

Dr. Donepudi Pavan Kumar, Email: pavandonepudi@ yahoo.com

Copyright: (C) the author(s), publisher and licensee Medip Academy. This is an openaccess article distributed under the terms of the Creative Commons Attribution NonCommercial License, which permits unrestricted noncommercial use, distribution, and reproduction in any medium, provided the original work is properly cited.

\begin{abstract}
Background: Acne vulgaris is one of the most common dermatological disorder affecting the pilo sebaceous glands resulting in their blockage or inflammation. Symptoms of acne may include local erythema and tenderness and pain. Medication include benzoyl peroxide, retinoids, salicylic acid, alpha hydroxy acid, nicotinamide, azelaic acid, anti-seborrheic medications, hormonal treatment, anti-androgen medications and keratolytic soaps.

Methods: About 166 patients who were treated for acne vulgaris were included into the study after taking the informed consent from the patients. This study was approved by the Institutional Ethics Committee. The demographic details of the patients with regards to their, age sex, weight, BMI were taken. The acne was medically diagnosed, and the grade was assessed.

Results: Out of the 166 patients included into the study, $92(55 \%)$ were females while $74(45 \%)$ were males and the mean age was $25.4 \pm 1.6$ of the patients belonged to the middle class. Of the patients, most of them were adolescents or less than 25 years of age (54.2\%). 64 of the patients were between 26-45 years while only 12 were $>45$ years of age. A total of 521 drugs were prescribed. Of them, $37.6 \%$ were through the oral route and $62.4 \%$ were topical the most common prescribed drugs were antimicrobials, both topical and oral. Conclusions: The multidrug prescription in most of the cases can be rationalized if a drug monitoring system can be effectively put into place. This would not only reduce the number of drugs per prescription but also the cost of treatment.
\end{abstract}

Keywords: Acne vulgaris, Dermatological disorder, Prescriptions

\section{INTRODUCTION}

Skin diseases, especially in the developing countries is one of the major causes of morbidity in the outpatient wards. It was said to be the $18^{\text {th }}$ largest cause of morbidity globally and the $4^{\text {th }}$ largest cause of nonfatal diseases in $2010 .{ }^{1}$ Acne vulgaris is one of the most common dermatological disorder affecting the pilo sebaceous glands resulting in their blockage or inflammation. It is mostly seen to affect teenagers attaining puberty. ${ }^{2}$ It is estimated to affect 80 $90 \%$ of the teenagers. It is normally characterized by the formation of papules, pustules, inflammatory and noninflammatory lesions, affecting mainly the face and upper trunk. This results in abnormal sebum production and hyperkeratinisation of the follicles and bacterial infection. ${ }^{3,4}$

Acne develops due to hyperproliferation of the follicular epidermis with plugging of the follicle, excess sebum production or due to the presence of Propionibacterium acnes, which is a commensal bacteria, or due to inflammation. ${ }^{5}$ In addition, drugs containing isoniazid, 
corticosteroids, phenytoin, lithium, anabolic steroids and also oral contraceptives which have high androgenic activity also can result in acne. Thus, areas where these is a dense accumulation of the sebaceous glands, such as face, trunk, back, acne appears. ${ }^{6}$

Symptoms of acne may include local erythema and tenderness, and pain. Medication include benzoyl peroxide, retinoids, salicylic acid, alpha acid, nicotinamide, azelaic acid, anti-seborrheic medications, hormonal treatment, anti-androgen medications and keratolytic soaps. In case of bacterial infections, antibiotics are prescribed. ${ }^{7}$ These can be topical, such as erythromycin and clindamycin or systemic like tetracycline (250-500 mg BD) or doxycycline (100 mg BD). In case antibiotics are not useful, hormonal therapy may be given in women with oral contraceptives, which have been found to be useful. ${ }^{8}$

Synthetic retinoid isotretinoin in used in case of severe acne. But this treatment should be properly regulated as there are chance of adverse reactions. ${ }^{8}$ However, care must be taken against improper and irrational use as it may lead to the ineffectiveness of the medications. Such unnecessary prescriptions would ultimately result in adverse effects, not to mention the increased financial burden on the patient. ${ }^{5}$

This study was done to assess the drugs prescribed for acne among the patients in NRI Medical College and Hospital, Guntur, Andhra Pradesh, India.

\section{METHODS}

This study was done by the Department of Pharmacology on the patients attending the outpatient wards in NRI Medical College and Hospital, Guntur, Andhra Pradesh, India during the period December 2016 to March 2018. This hospital based observational study was done on 166 patients who were treated for acne vulgaris and were included into the study after taking the informed consent from the patients. This study was approved by the Institutional Ethics Committee. All patients attending the hospital for any other complaints and symptoms other than acne were excluded from the study. The demographic details of the patients with regards to their, age sex, weight, BMI were taken.

The acne was medically diagnosed, and the grade was assessed as grade 1 for comedones and occasional papules, as grade 2 for papules with comedones and occasional pustules, as grade 3 in case of prominent pustules with abscesses and nodules and as grade 4 for cysts and abscesses with scarring. Other details such as site of involvement was also taken.

Prescription details such as the drugs that were prescribed by the clinicians, dose and quantity, strength of the drug and treatment as well as other instructions to the patients were also noted. The study data obtained was statistically analysed on Microsoft Excel using SPSS software.

\section{RESULTS}

Out of the 166 patients included into the study, $92(55 \%)$ were females while 74 (45\%) were males (Figure 1).

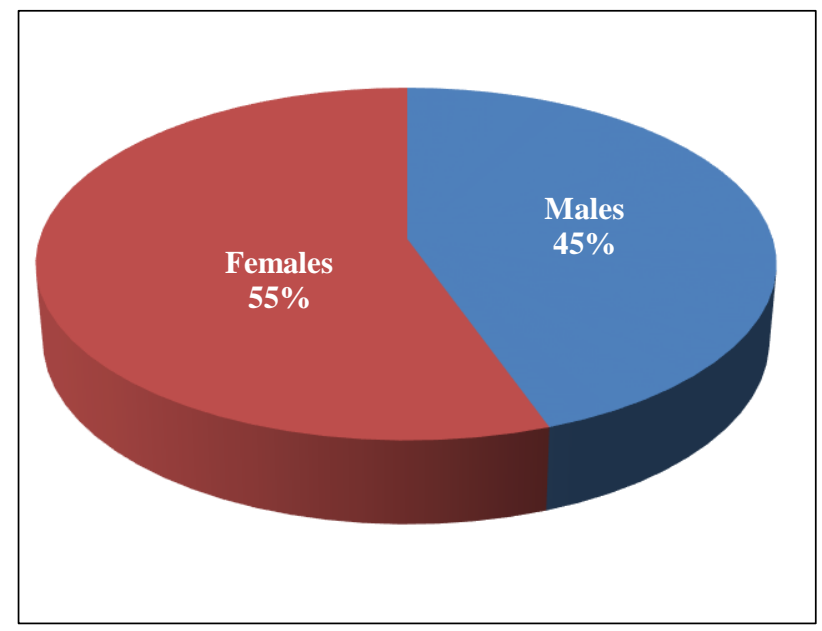

Figure 1: Sex wise distribution of patients with acne.

The mean age of all the 166 patients in the study was $25.4 \pm 1.6$. Most of the patients were unmarried $(61.4 \%)$ and many of them were students $(59.03 \%) .23 .5 \%$ of them were housewives. $96(57.8 \%)$ of them were non vegetarians while $72(42.2 \%)$ were pure vegetarians. Most of the patients belonged to the middle class $(71.7 \%)$ and many were underweight $(49.4 \%)$ (Table 1$)$.

Table: 1: Demographic details of the patients.

\begin{tabular}{|lll|}
\hline Details & & Number \\
\hline Mean age & & $24.4 \pm 1.6$ \\
\hline \multirow{3}{*}{ Marital status } & Married & $64(38.6 \%)$ \\
\cline { 2 - 3 } & Unmarried & $102(61.4 \%)$ \\
\hline \multirow{3}{*}{ Food habits } & Students & $98(59.03 \%)$ \\
\cline { 2 - 3 } & Housewives & $39(23.5 \%)$ \\
\cline { 2 - 3 } & Employed & $12(7.2 \%)$ \\
\cline { 2 - 3 } Socioecenomic & Unemployed & $17(10.2 \%)$ \\
\hline \multirow{2}{*}{ status } & Vegetarians & $70(42.2 \%)$ \\
\hline \multirow{3}{*}{ BMI } & Non-Vegetarians & $96(57.8 \%)$ \\
\cline { 2 - 3 } & Lower & $31(18.7 \%)$ \\
\cline { 2 - 3 } & Middle & $119(71.7 \%)$ \\
\hline & Upper & $16(9.6 \%)$ \\
\cline { 2 - 3 } & Underweight & $82(49.4 \%)$ \\
\cline { 2 - 3 } & Oormal weight & $31(18.7 \%)$ \\
\cline { 2 - 3 } & Oberweight & $26(15.7 \%)$ \\
\hline
\end{tabular}

Of the patients, most of them were adolescents or less than 25 years of age $(54.2 \%)$. 64 of the patients were between 26-45 years while only 12 were $>45$ years of age. In all the 
categories, females were more than the number of males with acne (Figure 2).

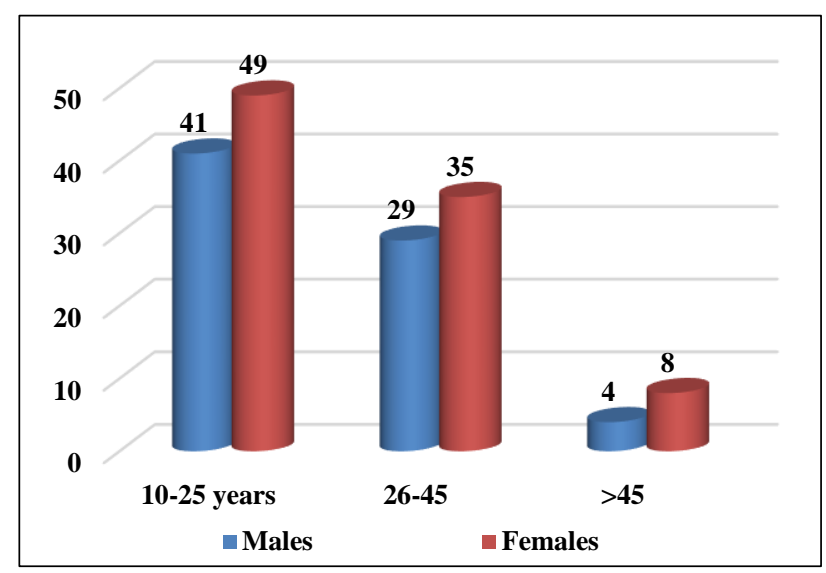

Figure 2: Age wise distribution of patients.

For the 166 patietns, a total of 521 drugs were prescribed. Of them, $196(37.6 \%)$, were through the oral route and 325 $(62.4 \%)$ were topical (Table :2).

Table 2: Prescription analysis.

\begin{tabular}{|ll|}
\hline Parameter & Number \\
\hline No of prescriptions & 166 \\
\hline Total drugs prescribed & 521 \\
\hline Total drugs though oral route & $196(37.6 \%)$ \\
\hline Total topical drugs & $325(62.4 \%)$ \\
\hline No of drugs per prescription (Average) & 3.14 \\
\hline No of fixed drug combinations & $87(16.7 \%)$ \\
\hline
\end{tabular}

Table: 3: Drugs prescribed.

\begin{tabular}{|ll|l|}
\hline Drugs & $\begin{array}{l}\text { Type of } \\
\text { application }\end{array}$ & $\begin{array}{l}\text { Number } \\
(\%)\end{array}$ \\
\hline $\begin{array}{l}\text { Benzoyl peroxidase }(2.5 \%, \\
5 \%)\end{array}$ & Topical & $73(14 \%)$ \\
\hline Adapalene & Topical & $38(7.3 \%)$ \\
\hline Tretinoin & Topical & $51(9.8 \%)$ \\
\hline Clindamycin ointment/gel & Topical & $59(11.3 \%)$ \\
\hline Azithromycin gel/ointment & Topical & $42(8.1 \%)$ \\
\hline Azithromycin & Oral & $49(9.4 \%)$ \\
\hline Doxycycline & Oral & $38(7.3 \%)$ \\
\hline Nadifloxacin & Oral & $15(2.9 \%)$ \\
\hline Antifungals & Oral & $11(2.1 \%)$ \\
\hline Retinoids & Oral & $71(13.6 \%)$ \\
\hline Antihistamines & Oral & $74(14.2 \%)$ \\
\hline
\end{tabular}

The most common prescribed drugs were antimicrobials, both topical and oral. 73 (14\%) prescribed was benzoyl peroxidase, while $38(7.3 \%)$ was adapalene. $59(11.3 \%)$ and $59(11.3 \%)$ was azithromycin and clindamycin ointment/gel for topical use respectively and $49(9.4 \%)$ azithromycin $38 \quad(7.3 \%)$ doxycycline, $15 \quad(2.9 \%)$ nadifloxacin all of which were oral, amounting to 203 (39\%) antibacterial and $11(2.1 \%)$ antifungals (Table 3$)$.

\section{DISCUSSION}

About $10-30 \%$ of the patients attend a clinic with skin disorders and since these disorders are easily visible, cause a great deal of discomfort and embarrassment to them. It is estimated that adolescents, contribute about $85-90 \%$ of the patients with acne. ${ }^{9,10}$ The onset of acne in boys is said to be 12 years and in girls, it is around 11 years. ${ }^{11,12}$ Since, it is found to last longer, the average age when it effects is a little higher. In the present study, the mean age to be affected was $24.4 \pm 1.6$ years, while the majority of the patients were below 25 years of age. In a study by Gupta et al, most of the patients were below 20 years of age with the mean age being around corroborating present study. ${ }^{3}$ Kaur $\mathrm{S}$, Kumar S et al, and Sharma V et al, also reported similar results. ${ }^{8,13,14}$ Present showed that the change of hormones during puberty and after plays a major role in the production of acne..$^{5}$

The cause of acne is also due to various reasons including follicular hyperkeratinization, abnormal sebum production, inflammation and infection with bacteria such as Propionibacterium acnes. ${ }^{15}$

The prevalence of acne was seen slightly more in females rather than males and this was corroborated with other studies. ${ }^{16-18}$ However, in a study by Nandini et al, the prevalence was seen more in males during the adolescent age while the trend shifted towards females with increase in age. ${ }^{18,19}$ The increased prevalence of females having acne was attributed to the presence of humidity while cooking. ${ }^{17-20}$

The mean age of all the 166 patients in the study was 25.4 \pm 1.6. Most of the patients were unmarried (61.4\%) and many of them were students (59.03\%). $23.5 \%$ of them were housewives. $96(57.8 \%)$ of them were non vegetarians while $72(42.2 \%)$ were pure vegetarians. Most of the patients belonged to the middle class $(71.7 \%)$ and many were underweight. In a study by Kumar S et al, $89.49 \%$ belonged to the middle class while a study by Narwane SP et al, reported $84.66 \%$ to be from this class, showing that people of his class were more commonly affected. ${ }^{13,21}$

A total of 521 drugs were prescribed for the patients in the present study. Of them, 196 (37.6\%), were through the oral route and $325(62.4 \%)$ were topical. The average drugs per patient was 3.14 . In a study by Nandini et al, the oral drugs given were $36.36 \%$ and topical formulations were $63.63 \%$ which was on par with this study. ${ }^{15}$ In another study by Tikkoo D et al, the oral were $38.1 \%$ and topical were $60.2 \%$ while Kumar S et al, reported oral formulation of $40.02 \%$ and topical $57.01 \% .^{13,22}$ The average drug per prescription was 1.77 in a study by Pooja et al, 2.5 in a study by Khunger $\mathrm{N}$ et al, 4.77 in a study by Kumar $\mathrm{S}$ et al. ${ }^{13,15,23}$ 
The fixed drug combinations in this study were $16.7 \%$ as compared to $4.39 \%$ in a study by Khunger $\mathrm{N}$ et al, and $26.78 \%$ in a study by Pooja $\mathrm{M}$ et al. ${ }^{15,23}$

A fixed dose combination is usually given, keeping in mind the pharmacokinetics and pharmacodynamics of the drugs so that the combination drug would produce a synergistic effect without a toxic effect. Moreover, since it is more convenient, there is a better compliance by the patients. ${ }^{24}$ 26.

The most common prescribed drugs were antimicrobials, both topical and oral. $73(14 \%)$ prescribed was benzoyl peroxidase, while 38 (7.3\%) was Adapalene. 59 (11.3\%) and $59(11.3 \%)$ was azithromycin and clindamycin ointment/gel for topical use respectively and $49(9.4 \%)$ azithromycin 38 (7.3\%) doxycycline, $15 \quad(2.9 \%)$ nadifloxacin all of which were oral, amounting to 203 $(39 \%)$ antibacterial and $11(2.1 \%)$ antifungals. This was in accordance with a similar study by Gupta et al. ${ }^{3}$

In most of the cases, there was clearing of acne but in a few cases the result was limited. This could be due to the noncompliance of the medications by the patients.

\section{CONCLUSION}

One of the most common disorder that impacts the quality of life and psychological wellbeing of the patient is acne vulgaris. The multidrug prescription in most of the cases can be rationalized if a drug monitoring system can be effectively put into place. This would not only reduce the number of drugs per prescription but also the cost of treatment. This would call for the involvement of the hospital management to formulate a suitable system which will enable the physicians to restrict their prescriptions to essential drugs.

\section{Funding: No funding sources}

Conflict of interest: None declared

Ethical approval: The study was approved by the Institutional Ethics Committee

\section{REFERENCES}

1. Hay RJ, Johns NE, Williams HC, Bolliger IW, Dellavalle RP, Margolis DJ, et al. The global burden of skin disease in 2010: an analysis of the prevalence and impact of skin conditions. $\mathrm{J}$ Investigative Dermatol. 2014;134(6):1527-34.

2. Danby FW. Acne: diet and acnegenesis. Ind Dermatol Online J. 2011;2:2-5.

3. Gupta A, Dhande PP. Drug utilizing pattern for acne vulgaris in a tertiary care teaching hospital. J Basic Clin Pharma. 2017;8:230-4.

4. Thappa DM. Microanatomy of the skin. In.: Thappa DM, eds. Essential in Dermatology Microanatomy of the Skin. 2nd ed. New Delhi: Jaypee Brothers Medical; 2009:1-8.
5. Dawson AL, Dellavalle RP. Acne vulgaris. BMJ. 2013;346:f2634.

6. Thiboutot D, Gollnick H, Bettoli V, Dréno B, Kang S, Leyden JJ, et al. New insights into the management of acne: an update from the global alliance to improve outcomes in acne group. J Am Acad Dermatol. 2009;60(5):S1-50.

7. Kubba R, Bajaj AK, Thappa DM, Sharma R, Vedamurthy $M$, Dhar $S$, et al. Acne in India: guidelines for management-IAA consensus document. Ind J Dermatol Venereol Leprol. 2009;75:1-64.

8. Kaur S. Topical corticosteroids usage in dermatology. Int J Clin Pharm Therap Toxic. 1991;29:48-50.

9. Stathakis V, Kilkenny M, Marks R. Descriptive epidemiology of acne vulgaris in the community. Aus J Dermatol. 1997;38:115-23.

10. Kraning KK, Odland GF. Prevalence, morbidity, and cost of dermatological diseases. J Invest Dermatol. 1979;73:395-513.

11. Dreno B, Poli F. Epidemiology of acne. Dermatol. 2003;206:7-10.

12. Schäfer T, Nienhaus A, Vieluf $D$, Berger J, Ring J. Epidemiology of acne in the general population: the risk of smoking. Brit J Dermatol. 2001;145:100-4.

13. Kumar S, Dutta S, Beg MA, Mehta AK, Anjoom M, Sindhu S. Drug utilization pattern in acne vulgaris in skin outpatients department of a tertiary care teaching hospital at Dehradun, Uttarakhand. Int J Med Sci Pub Heal. 2014;3:855-8.

14. Sharma V, Bajpai A. Study of prescription pattern for acne vulgaris in dermatology OPD in a tertiary care teaching hospital. Int J Med Res Prof. 2016;2(2):3169.

15. Khunger N, Kumar C. A clinico-epidemiological study of adult acne: Is it different from adolescent acne? Ind J Dermatol Venereol Leprol. 2012;78:33541.

16. Williams C, Layton AM. Persistent acne in women. Implications for the patient and for therapy. Am J Clin Dermatol. 2006;7(5):281-90.

17. Goulden V, Clark S, Cunliffe W. Post adolescent acne: a review of clinical features. Brit J Dermatol. 1997;136(1):66-70.

18. Nandini T, Kumbar SK, Padmanabha TS, Krishna P, Narendra G. A prospective study of pattern of prescription for acne vulgaris in a tertiary care hospital: an observational study. Int J Basic Clin Pharmacol. 2016;5:2357-61.

19. Zaenglein AL, Graber EM, Thiboutot DM, Strauss JS. Acne vulgaris and acneiform eruption. In: Wolff K, eds. Fitzpatrick's dermatology in General Medicine. 7th ed. New York: Mcgraw Hill; 2008:687-703.

20. Goulden V, Stables GI, Cunliffe WJ. Prevalence of facial acne in adults. J Am Acad Dermatol. 1999;41(4):577-80.

21. Narwane SP, Patel TC, Shetty YC, Chikhalkar SB. Drug utilization and cost analysis for common skin diseases in dermatology OPD of an Indian tertiary care hospital: a prescription survey. Brit J Pha Res. 2011;1:9-18. 
22. Tikoo D, Chopra SC, Kaushal S. Evaluation of drug use pattern in dermatology as a tool to promote rational prescribing. JK Sci. 2011;13:128-31.

23. Pooja M, Holla R, Girisha BS, Puneeth A. A study of prescription pattern in the drug therapy of acne vulgaris at a tertiary care hospital in Mangalore, India. Int J Basic Clin Pharmacol. 2018;7:80-6.

24. Santosh K, Shaktibala D, Mirza AB, Anil KM, Mohammed A, Saubhagya S. Drug utilization pattern in acne vulgaris in skin outpatients department of a tertiary care teaching hospital at Dehradun, Uttarakhand. Int J Med Sci Pub Heal. 2014;3(7):36.

25. Nibedita P, Jena M, Panda M, Dash M. A study on the prescribing pattern of drugs for acne in a tertiary care teaching hospital in Odisha. J Clin Diagn Res. 2015;9(3):4-6.

26. Poudel A, Palaian S, Shankar PR, Jayasekara J, Izham MIM. Irrational fixed dose combinations in Nepal: need for intervention. Kathmandu Univ Med J. 2008;6(3):399-405.

Cite this article as: Kumar PK. Patterns of acne prescriptions: a study in a tertiary care unit. Int $\mathbf{J}$ Basic Clin Pharmacol 2019;8:1554-8. 